\title{
Teoría positivista del Derecho y derechos naturales en H. L. A. HART
}

\section{Jose Antonio Ramos Pascua}

Profesor titular de Filosofía del Derecho

Universidad de Salamanca

Trataré de hacer una valoración general de la obra iusfilosófica de H. L. A. Hart, examinando, entre otras cosas, el difícil maridaje entre los elementos que menciona el título de este artículo. Partiré de una idea o criterio para la valoración de los sistemas iusfilosóficos que el Profesor Delgado Pinto propuso recientemente en su discurso de aceptación del Doctorado Honoris Causa por la Universidad Carlos III de Madrid.

Según esa idea, muy razonable, a mi juicio, la clave para valorar la filosofía del Derecho de cualquier autor debe buscarse, no tanto en el bando al que se afilie en el eterno y ya algo aburrido intercambio de golpes entre iusnaturalistas y positivistas, cuanto en el hecho de que ofrezca o no una respuesta satisfactoria y coherente a las tres grandes cuestiones iusfilosóficas: ¿Qué es el Derecho? (la pregunta central de la Teoría del Derecho) ¿Qué debe ser o cómo debe ser el Derecho? (la pregunta a la que intenta responder la Teoría de la justicia) y ¿Cómo razonan o deben razonar los juristas? (la pregunta fundamental de la metodología o Teoría de la ciencia jurídica). Las respuestas a estas tres grandes cuestiones deben ser, en primer lugar, congruentes entre sí. En segundo lugar, deben ser satisfactorias en el sentido de que han de reflejar adecuadamente la realidad del fenómeno jurídico, dar cuenta de manera fiel de la práctica o vida real del Derecho, y quizá también encauzarla hacia su mejor desarrollo posible. 
Si pensamos, por ejemplo, en la filosofía del Derecho de H. Kelsen, y sin dejar de admirar el impresionante esfuerzo intelectual que en ella cristaliza, advertiremos que su teoría de la justicia, expresión del irracionalismo ético que profesaba, aunque es coherente con su teoría del Derecho, nos deja hoy profundamente insatisfechos si la confrontamos con la plausible rehabilitación de la razón práctica lograda por J. Habermas y K. O. Apel o con las brillantes aportaciones de J. Rawls y tantos otros. ¿Y qué decir de su teoría de la ciencia jurídica? Sin duda también es coherente con su teoría pura del Derecho. Pero la coherencia con el dogma de la pureza que excluye de la ciencia jurídica todo juicio de valor y cualquier referencia a elementos fácticos ajenos a lo normativo, obliga a Kelsen a reducir, y en realidad a condenar, la labor del científico del Derecho a una estéril descripción de normas sin referencia posible a la realidad social en que se aplican, con sus necesidades, propósitos y valores. No parece ésta una descripción adecuada de la forma efectiva en que actúan y razonan los científicos del Derecho. Por todo lo anterior, la filosofía del Derecho de Kelsen puede considerarse irremediablemente fracasada. Cosa que no obsta para reconocer que hay mucho de valor perdurable en su obra, verdaderamente titánica.

Pero centrémonos en Hart, el otro gran teórico iuspositivista del siglo XX, que ofrece una filosofía del Derecho alternativa a la de Kelsen rechazando muchos de los dogmas o prejuicios que atenazan la obra de éste, tales como el ya citado irracionalismo ético, el esquematismo reduccionista en cuanto a la concepción de las normas jurídicas, y sobre todo, el voto de pureza. Aunque también se proclama positivista, como Kelsen, y nunca renuncia a esta profesión de fe, se inspira como buen inglés en tradiciones propias y distintas. Dos son las corrientes de pensamiento que influyen y confluyen en la obra de nuestro autor. La primera es la peculiar filosofía del Derecho positivista inglesa, conocida como Jurisprudencia analítica, que tiene su principal precursor en Th. Hobbes, su fundador en J. Bentham y su sistematizador más 
conocido en J. Austin. Hart, constante admirador y estudioso de la obra de J. Bentham, concibe su propio pensamiento como una versión corregida y actualizada de aquella vieja escuela positivista, de la que se considera heredero y continuador. Quizá sea por eso mismo, porque él concibe su misión filosófico-jurídica como una especie de puesta al día de la Jurisprudencia analítica, por lo que mantiene imperturbablemente su fidelidad a la causa positivista pese a que, como sostendré después, la lógica interna de su propio pensamiento parece empujarle más allá del positivismo.

La otra gran corriente de pensamiento en la que Hart participa directamente y de la que toma las herramientas conceptuales que le permiten reconstruir críticamente el positivismo jurídico inglés es, como bien se sabe, la filosofía analítica del lenguaje ordinario. Una filosofía que, inspirada en el pensamiento del segundo Wittgenstein, tuvo una extraordinaria floración en Inglaterra, sobre todo durante las décadas centrales del pasado siglo ${ }^{1}$. Curiosamente, Hart se introdujo en los cenáculos de esta nueva filosofía durante la Segunda Guerra Mundial, que pasó en el Servició de Inteligencia Británico, adonde los ingleses, con esa peculiar lógica suya o quizá más bien sentido del humor, destinaban a los filósofos. En el Servicio de Inteligencia, Hart conoció y trabó amistad con algunos de los mejores filósofos analíticos del lenguaje de la escuela de Oxford, y después de la guerra trabajó durante algunos años como profesor de filosofía colaborando estrechamente con John Langshaw

1 Cfr. HART, H. L. A., "Ihering's Heaven of Concepts and Modern Analytical Jurisprudence", en Essays in Jurisprudence and Philosophy, Oxford, Clarendon Press, 1983, pp. 271 y ss., donde distingue dos fases dentro de la Jurisprudencia analítica. Asocia la primera fase con los nombres de J. Bentham y J. Austin; mientras que la segunda, en la que obviamente él mismo quedaría encuadrado como principal exponente, se inspira en la filosofía analítica del lenguaje, cuyos representantes más fecundos fueron L. Wittgenstein y J. L. Austin. Vid. también, al respecto, entre otros, MacCormick, N., H. L. A. Hart, London, Edward Arnold, 1981, pp. 12-9 ("Analytical Jurisprudence and Linguistic Philosophy"); Páramo Argüelles, J. R., H. L. A. Hart y la teoría analítica del Derecho, Madrid, C. E. C., 1984, pp. 1-155. 
Austin, una de las figuras más influyentes en el pensamiento inglés de posguerra ${ }^{2}$.

En mi opinión, muchos de los conceptos o ideas que Hart extrae de la filosofía analítica del lenguaje y con los que intenta corregir y actualizar el viejo positivismo jurídico inglés son, en el fondo, incompatibles con esta corriente iusfilosófica e introducen en ella una especie de bomba de relojería que explica su crisis posterior. Así como las Investigaciones filosóficas del segundo Wittgenstein rompían con el Tractatus del primero, que concordaba en buena medida con el positivismo radical del empirismo lógico, las aportaciones de la filosofía analítica del lenguaje ordinario, que se mueven en la misma línea del segundo Wittgenstein, difícilmente podían apuntalar y no desmoronar una teoría del Derecho estrictamente positivista e incluso empirista, como la de Bentham y Austin ${ }^{3}$.

En aras de la agilidad expositiva, imprescindible cuando se trata de realizar un balance general, destacaré, como apoyo de la afirmación anterior, sólo tres conceptos, aunque conceptos clave, de la teoría del Derecho de Hart, que permiten apreciar tanto su trascendencia como sus

2 Vid. sobre éste y otros muchos aspectos de la vida de Hart, la reciente biografía de LACEY, N., A Life of H. L. A. Hart. The Nightmare and the Noble Dream, Oxford, OUP, 2004.

3 OrRego, C., H. L. A. Hart. Abogado del positivismo jurídico, Pamplona, EUNSA, 1997, p. 10 (y más ampliamente en el capt. V), va más allá, afirmando que la filosofía analítica contemporánea en la que Hart se basa contiene elementos que tienden a la explicación metafísica clásica y al iusnaturalismo. "Sin embargo, Hart no saca las consecuencias de esos elementos, con lo cual su filosofía incurre en diversos círculos viciosos difíciles de comprender". La explicación de ese "equilibrismo de elementos incompatibles" (p. 5) que ha de hacer Hart para mantenerse fiel a toda costa al positivismo jurídico, debe buscarse, según sostiene Orrego en el capt. VI (esp. pp. 372 ss.), en su voluntad de defender la tradición de pensamiento utilitarista-positivista que justificaba sus propias convicciones morales, sobre todo en materia de religión y moralidad sexual; unas convicciones que no habrían podido encontrar abrigo en el iusnaturalismo clásico. En mi opinión, esta conclusión, que se presenta como la tesis central del libro (p. 393), es un tanto arriesgada. Se mueve en el terreno resbaladizo de las convicciones y características personales, de la psicología individual, cuyo conocimiento podría contribuir a explicar por qué un individuo abraza una determinada doctrina, pero no sirve para hacer más ni menos sólida la doctrina en cuestión, y por tanto es filosóficamente irrelevante. 
tensiones y debilidades en cuanto teoría que pretende seguir siendo positivista.

El primero de estos conceptos clave procedentes de la filosofía analítica del lenguaje es el de la dimensión interna del Derecho, que es la dimensión típicamente normativa. Supone, como es bien sabido, la distinción entre dos posibles actitudes o puntos de vista frente a las normas, que se reflejan en diferentes formas de hablar. El punto de vista externo es el adoptado por quienes sólo captan las regularidades de comportamiento provocadas por las normas, es decir, por quienes sólo describen fenómenos empíricamente verificables. Y no se olvide que la teoría del Derecho de Bentham y Austin se construye exclusivamente a partir de este tipo de fenómenos. Fenómenos tales como los de mandato, amenaza, probabilidad de sufrir un castigo, hábito de obediencia, etc. Desde un punto de vista puramente externo, como éste, es imposible, reconoce Hart, comprender adecuadamente la realidad del Derecho. El otro punto de vista es el interno, el punto de vista del partícipe en la vida del Derecho, el punto de vista de quien acepta o interioriza las normas como pautas de conducta recíprocamente exigibles entre los miembros del grupo social, y se apoya en ellas para expresar críticas hacia las conductas desviadas o para reclamar a cualquiera el comportamiento correcto.

La reflexión sobre las implicaciones del aspecto interno del Derecho permite a Hart aclarar conceptos o fenómenos jurídicos que el positivismo decimonónico inglés explicaba de manera insatisfactoria, como por ejemplo, la noción del deber jurídico, concebida como la probabilidad de sufrir los males o castigos previstos por las normas jurídicas en caso de incumplimiento. Esta concepción confunde, según advierte agudamente Hart, lo que es tener una obligación con lo que es verse obligado (en el sentido de coaccionado). Para Hart, sólo existe una verdadera obligación cuando está justificada la exigencia y hasta la imposición de una determinada conducta, y lo está porque el grupo social acepta una norma como modelo de comportamiento intersubjetivamente exigible. Pero ¿qué implicaciones tiene tal 
aceptación? ¿Qué implicaciones tiene la dimensión interna del Derecho?

Muchos sostienen que implica, entre otras cosas, el reconocimiento de que existe una relación necesaria entre el Derecho y la moral, porque la razón por la cual se acepta el orden jurídico como conjunto de pautas vinculantes no puede ser otra que el reconocimiento de su valor moral. Hart rechaza la conclusión anterior, porque es incompatible con la tesis central que atribuye al positivismo jurídico, la tesis de que no existe relación necesaria alguna entre el Derecho y la moral. A su juicio, las razones por las que se adopta el punto de vista interno respecto al Derecho (o para ser más precisos, la razón por la que lo adoptan los jueces respecto a la regla de reconocimiento, aceptándola) pueden ser muy variadas. Pueden ser razones morales, en efecto, pero también puede aceptarse el Derecho por inercia, por miedo, por intereses egoístas, etc. ${ }^{4}$. Esta explicación, que puede describir de manera realista las diversas actitudes subjetivas eventualmente adoptadas por los ciudadanos frente a las normas jurídicas, no resulta válida para justificar la adopción de una actitud normativa. En efecto, no parece aceptable que la actitud típicamente interna o normativa de exigir una conducta a otro o criticarle por no haberla realizado, especialmente cuando es un juez quien la adopta al condenar a una persona por infringir alguna norma, se pueda apoyar legítimamente en el interés egoísta o en el miedo o en cualquier otra razón carente de fuerza justificatoria.

Si alguien aceptara el carácter vinculante de las normas jurídicas por su propia conveniencia egoísta, en todo caso tendría que fingir que la razón es otra, de tipo moral, puesto que mal podría exigir a los demás la conducta correcta apelando a su propio interés, dado que las infracciones de los otros también obedecerán a motivos interesa-

${ }^{4}$ Cfr. Hart, H. L. A., "Legal and Moral Obligation", en Essays in Moral Philosophy, Seattle, Univ. Of Washington Press, 1958, p. 93; El concepto de Derecho, trad. de G. R. Carrió, Buenos Aires, Abeledo-Perrot, 1963, pp. 250-1; "Commands and Authoritative Legal Reasons", en Essays on Bentham. Jurisprudence and Political Theory, Oxford, Clarendon Press, 1982, pp. 256-7 y 265. 
dos. Quiere esto decir que las diversas razones extramorales que apunta Hart son parasitarias o dependientes de la razón moral, porque de un modo $u$ otro la presuponen o necesitan. Seguramente es verdad que muchos individuos, quizá la mayoría, acepta las normas por inercia, irreflexivamente, pero si reflexionaran y se preguntaran por la razón que justifica su actitud, tendrían que acudir a una razón moral, porque sólo las razones morales tienen capacidad para justificar últimamente las exigencias o las críticas a la conducta de otro ${ }^{5}$.

Parece difícil, en definitiva, ahondar en la dimensión interna del Derecho sin terminar descubriendo importantes conexiones del mismo con la moral. Al colocar en el centro mismo de su teoría el peculiar sentido que el Derecho tiene para el partícipe, para quien lo acepta como orden vinculante, y especialmente para el juez, Hart ha enriquecido extraordinariamente nuestra comprensión del fenómeno jurídico, pero ha debilitado las defensas del positivismo.

Algo similar ocurre con el segundo concepto que vamos a destacar de su pensamiento, y que también procede de la filosofía analítica del lenguaje. Me refiero a la idea de la textura abierta del Derecho, una idea que Hart parece haber extraído de la obra de F. Waismann, otro seguidor de Wittgenstein ${ }^{6}$. El Derecho tiene textura abierta porque se expresa mediante un instrumento que también la tiene: el

${ }^{5}$ Cfr. Delgado Pinto, J., "El deber jurídico y la obligación de obedecer al Derecho", en Obligatoriedad y Derecho. Actas de las XII Jornadas de Filosofía Jurídica y Social, Oviedo, 1991, pp. 36-7; "La obligatoriedad del Derecho y la insuficiencia tanto del positivismo jurídico como del iusnaturalismo", en Revista de Ciencias Sociales (Valparaíso, Chile), no 41, 1996, p. 116; BAYon MoHino, J. C., La normatividad del Derecho: deber jurídico y razones para la acción, Madrid, C. E. C., 1991, pp. 737-9; RuIz MANero, J., Jurisdicción y normas. Dos estudios sobre función judicial y teoría del Derecho, Madrid, C. E. C., 1990, pp. 177-9; Ramos PaScUA, J. A., La regla de reconocimiento en la teoría jurídica de H. L. A. Hart, Madrid, Tecnos, 1989, pp. 195-9.

${ }^{6}$ Cfr. HaRT, H. L. A., El concepto de Derecho, op. cit., pp. 155-169; "Problems of the Philosophy of Law", en Essays in Jurisprudence and Philosophy, loc. cit., pp. 103 y ss.; "Positivism and the Separation of Law and Morals", en Essays in J..., loc. cit., pp. 63 y ss. Vid. también WaISSMan, F., "Verifiability", en Proceedings of the Aristotelian Society, Suppl. vol. XX, 1946. 
lenguaje. Es decir, las normas jurídicas contienen términos generales que designan tipos abstractos de cosas, actos o hechos. Sin embargo, los casos reales, los actos y hechos jurídicamente relevantes que se producen en la vida social son actos o hechos concretos, con sus rasgos propios y específicos, y no siempre es posible saber con certeza si cada hecho real es o no reductible o subsumible en el hecho tipo fijado por la norma. La consecuencia de lo anterior es que toda norma jurídica tiene, junto a un núcleo de significado más o menos claro, una zona de penumbra en la que resulta difícil determinar en qué sentido debe aplicarse. Es cierto que a través de las técnicas ordinarias de interpretación se pueden mitigar muchas de estas incertidumbres, pero nunca pueden eliminarse completamente.

El reconocimiento de la textura abierta o porosa del Derecho es el reconocimiento de su carácter inevitablemente limitado o insuficiente como orden regulador de la vida social. Es el reconocimiento de que sus normas están repletas, no ya de lagunas, puesto que hablamos de casos a los que las normas ofrecen respuesta, sino de charcos, por seguir con la metáfora acuática, pues aunque las normas responden, en muchos casos no se sabe muy bien qué decisión concreta debe extraerse de lo que responden. Dicho sin metáforas: el Derecho adolece de una profunda indeterminación, y gran parte de los conflictos que se plantean ante los tribunales son por ello lo que se ha dado en denominar "casos difíciles". Con la idea de la textura abierta, indeterminada o incierta del Derecho, Hart corrige las deficiencias del positivismo legalista o formalista del siglo XIX, que concebía el Derecho como un orden completo y cerrado de normas, mediante cuya aplicación mecánica el juez podía resolver todos los problemas jurídicos que se le plantearan. Frente a esta concepción insostenible, Hart reconoce plausiblemente el carácter abierto del sistema jurídico; cosa que parece de sentido común, pues el Derecho no puede operar en el vacío al margen de los otros subsistemas del sistema social.

Pero si el Derecho es un sistema abierto y tiene necesidad de que otros sistemas normativos, básicamente la moral, lo complementen, peligra otra vez la tesis positivista 
de la desconexión entre el Derecho y la moral. De nuevo advertimos cómo el pensamiento de Hart abre caminos que parecen alejarse del positivismo jurídico. Pero una vez más se niega a explorarlos refugiándose ahora en una de sus doctrinas más controvertidas: la doctrina de la discrecionalidad judicial, que él declara positivista seguramente porque le permite mantener la tesis de la separación entre el Derecho y la moral. La doctrina es bien conocida. Dado que el Derecho es incapaz de ofrecer una solución precisa para muchos conflictos jurídicos, el juez goza de libertad para resolverlos a su modo.

La discrecionalidad judicial creadora de Derecho, que hoy se presenta como una de las tesis básicas del positivismo jurídico, es en realidad de un positivismo bastante dudoso. En primer lugar porque histórica o tradicionalmente, como dije antes, el positivismo jurídico (al menos el continental) comenzó defendiendo todo lo contrario, y en segundo lugar porque traiciona el valor positivista por excelencia, el valor de la certeza. Obviamente, si la decisión de una parte significativa de los conflictos jurídicos depende de la discrecionalidad de los jueces, poca certeza y poca seguridad jurídica cabe esperar del Derecho. Pero hay algo peor que ser una doctrina de dudosa estirpe positivista, y es ser una doctrina escasamente convincente. No es casual que en esta doctrina se haya cebado exitosamente el ataque de R. Dworkin ${ }^{7}$.

Hart no deja de advertir, es cierto, que la discrecionalidad atribuida por él a los jueces no equivale a capricho irracional o mero arbitrio. La decisión del juez, aunque no pueda apoyarse en el Derecho, tendrá que apoyarse, según dice, en alguna buena razón que la justifique ${ }^{8}$. Por desgra-

7 Vid. Dworkin, R., Los derechos en serio, trad. de M. Guastavino, Barcelona, Ariel, 1984, esp. pp. 83 ss. y 130 ss.

8 Ya en El concepto de Derecho, op. cit., p. 312, afirmaba Hart que "a veces el juez tiene mucho más que libertad de interpretación. Cuando él considera que ninguna ley u otra fuente formal de Derecho determina la decisión del caso, puede fundar su fallo, por ejemplo, en un texto del Digesto o en la obra de algún jurista francés (...). El sistema jurídico no le obliga a usar estas fuentes, pero está aceptado como cosa perfectamente correcta que lo haga". En "El nuevo desafío al 
cia, no profundiza en el examen de esas razones en las que el juez habrá de apoyarse, pero si lo hiciera, probablemente volvería a tener problemas para mantener el dogma positivista de la separación entre el Derecho y la moral, porque difícilmente podría evitar la conclusión de que o bien esas razones son elegidas caprichosamente por el juez (en cuyo caso, volveríamos al arbitrio judicial, aunque algo disimulado o enmascarado) o bien son razones que se imponen por su propio valor, en cuyo caso sólo cabe hablar de discrecionalidad en un sentido débil, que equivale a simple ejercicio del juicio para hallar la razón más adecuada, que lógicamente será una razón moral, puesto que sólo desde la moral se pueden justificar decisiones que afecten a los derechos y los deberes de las personas.

En cualquier caso, es difícil negar la incomodidad provocada por la imagen del Derecho que resulta de combinar la tesis de la textura abierta con la tesis de la discrecionalidad judicial. En esa imagen se otorga a los jueces, al menos en alguna medida, el papel de inventores o creadores del Derecho; un papel que, como el propio Hart reconoce expresamente, los tribunales siempre niegan desempeñar, insistiendo en que su tarea es la de hallar y aplicar el Derecho existente y no la de crearlo ${ }^{9}$. Es una pena que, olvidando su metodología habitual, Hart haya preferido no extraer en este punto ninguna enseñanza del análisis del lenguaje ordinario de los jueces, limitándose a descalificarlo como mera retórica.

El tercer concepto clave de la Teoría del Derecho de Hart que me propongo repasar de forma tan esquemática como los anteriores, es el de la regla de reconocimiento ${ }^{10}$.

positivismo jurídico", trad. de L. Hierro, J. R. de Páramo y F. Laporta, en Siste$m a$, vol. 36, 1980, p. 9, reconoce Hart que si bien es cierto que, ante la indeterminación del Derecho, "el juez para decidir el caso debe ejercer su poder de creación de Derecho", "no debe hacerlo arbitrariamente: es decir, debe tener siempre algunas razones generales que justifiquen su decisión y actuar como lo haría un legislador consciente, decidiendo según sus propias creencias y valores".

${ }^{9}$ Cfr., p. ej., HART, H. L. A., "El nuevo desafío al positivismo jurídico", op. cit., pp. 9-10.

${ }_{10}$ Un examen más detallado puede encontrarse en mi trabajo La regla de reconocimiento en la teoría jurídica de H. L. A. Hart, Madrid, Tecnos, 1989. 
Esta regla, en la medida en que sirve para identificar las normas válidas del sistema jurídico, funciona como una especie de centinela o cierre de seguridad del mismo frente a las intromisiones de otros sistemas normativos. La idea de semejante regla, que tan buenos servicios presta a la concepción positivista del Derecho, parece inspirada más en la obra de otros destacados iusfilósofos positivistas, como Bentham ${ }^{11}$, Salmond, Hägerström o Kelsen y su famosa norma fundamental, que en la filosofía analítica del lenguaje, aunque su configuración concreta como práctica social de identificación de normas válidas tiene algo que ver con las especulaciones de Wittgenstein y sus seguidores sobre lo que implica seguir una regla y sobre las diferentes funciones de las reglas.

La regla de reconocimiento, al igual que la Grundnorm kelseniana, supone una corrección del positivismo jurídico decimonónico, que era incapaz de fundamentar o explicar adecuadamente la validez del Derecho, y apelaba para ello a hechos tales como el mero hábito de obediencia a un soberano. Pero ocurre que la regla de reconocimiento, como puso de relieve la crítica de R. Dworkin, que tiene aquí otro de sus blancos preferidos, plantea serios problemas. El principal es que, tal y como Hart parece configurarla, resulta incapaz de identificar la validez o relevancia jurídica de ciertos elementos del Derecho que, como los principios o valores superiores, no pueden identificarse mediante criterios puramente formales o "de pedigrí", sino que re-

11 En "The United States of America", en Essays on Bentham..., loc. cit., 1982 , p. 60, alude Hart a los intentos de Bentham de matizar su tesis de que el poder político supremo carece de límites jurídicos, reconociendo la existencia de principios "conforme a los cuales los jueces tratan la satisfacción de ciertas condiciones, tanto sustantivas como procedimentales, como criterios de validez de las normas dictadas por una legislatura, incluso aunque esos principios no son el producto de la voluntad del legislador soberano y por tanto no son Derecho conforme a una teoría estrictamente imperativa". Es significativo que este antecedente de la regla de reconocimiento en la teoría de Bentham se introduzca para remediar defectos de su estricta concepción positivista del Derecho. Más información sobre los antecedentes de la idea de regla de reconocimiento en los autores mencionados junto a Bentham puede encontrarse en la obra citada en la nota anterior (pp. 135 y ss.). 
quieren procedimientos más complejos, que incluyen valoraciones morales.

En sus réplicas a la crítica de Dworkin, Hart advierte, entre otras cosas, que la regla de reconocimiento puede contener también criterios materiales o de contenido. Una regla de reconocimiento podría exigir como requisito de validez, por ejemplo, y no se trata de un ejemplo de ciencia-ficción sino de algo que vemos en todos los modernos Estados constitucionales, que las normas jurídicas respeten el valor de la dignidad de la persona o los derechos humanos. También admite Hart que por muy complejo y consistente en valoraciones morales que sea el procedimiento necesario para identificar los principios jurídicos, la regla de reconocimiento podría perfectamente incluirlo entre sus requisitos o criterios de validez ${ }^{12}$. Con estas importantes concesiones se plantea de nuevo el problema de la evidente conexión entre Derecho y moral que implica una regla de reconocimiento así concebida. Pero una vez más Hart encuentra el modo de salir del trance sin dejar de ser positivista, argumentando que se trataría de una conexión sólo contingente y no necesaria.

Después de darle muchas vueltas a este argumento en el que Hart termina enrocándose siempre que ve peligrar el dogma positivista de la separación entre el Derecho y la moral, he llegado a la convicción (lo cual no significa que pueda demostrarlo convincentemente) de que estamos ante una especie de falacia o sofisma, una especie de truco de prestidigitación filosófica que impone la aceptación de una tesis contraria a la evidencia y al sentido común, la tesis de la separación entre Derecho y moral, por la sola razón de que la tesis contraria podría ser imprecisa en algún caso. Remedando a Bentham, que, como otros hacen con las mariposas, gustaba de cazar y clasificar falacias, consideraré el argumento de la contingencia y no necesi-

${ }^{12}$ Cfr. HaRT, H. L. A., "Lon L. Fuller: The Morality of Law", en Harvard Law Review, vol 78, 1965, p. 361; "El nuevo desafío al positivismo jurídico", op. cit., pp. 8 y 14-5; "Postscript" a la segunda ed. de The Concept of Law, Oxford, OUP, 1994, pp. 263 y ss.: "Principles and the rule of recognition". 
dad de las relaciones entre Derecho y moral como una manifestación de la que llamaré "falacia de o todos o ninguno". Según esta falacia, debe excluirse de la concepción o caracterización de un fenómeno cualquier rasgo del mismo cuya presencia no se pueda constatar en absolutamente todas las manifestaciones de ese fenómeno. No importa que sea un rasgo clave para la comprensión del fenómeno en cuestión. Si no comparece en todos los casos, debe excluirse por completo de la definición.

¿Puede esto considerarse aceptable? ¿El hecho de que existan caballos cojos nos obliga acaso a descartar la concepción del caballo como un animal veloz? Pues lo mismo ocurre con los llamados Derechos inicuos. De igual modo que es perfectamente válido concebir a los caballos como animales bien dotados para la carrera, aunque esto no sea un rasgo necesario sino sólo contingente, puesto que puede haber caballos cojos, enfermos o agonizantes que sean incapaces de correr, también se puede concebir el Derecho como un orden estrecha y profundamente conectado con la moral aun cuando pueda encontrarse algún ejemplo en que esto no ocurra, como el Derecho de la Alemania nazi, que es el ejemplo al que suele recurrirse casi siempre en estos casos. Un indicio más de lo rara avis que es un Derecho inmoral. Hay un pasaje muy revelador en el que Hart admite algo parecido a lo que acabo de afirmar. Dice literalmente lo siguiente: "La conexión entre Derecho y exigencias morales o principios de justicia es tan poco arbitraria y tan necesaria como la conexión entre el Derecho y las sanciones, y la búsqueda de respuesta a la cuestión de si esta necesidad es lógica (es decir, parte del significado del Derecho) o simplemente fáctica o casual bien puede dejarse como un inocente pasatiempo para los filósofos"13.

No sé por qué olvidó Hart en sus escritos posteriores esta sensata conclusión. Quizá pensó que siendo también él un filósofo formaba parte de su papel seguir enredando con aquel inocente pasatiempo. Lo que hay detrás del inocente

${ }^{13}$ Cfr. HaRt, H. L. A., "Positivism and the Separation of Law and Morals", op. cit., p. 79. 
pasatiempo, insisto en ello, es un auténtico embrollo lingüístico provocado por el uso de términos cargados de connotaciones logicistas y casi metafísicas, como contingencia y necesidad. Tenemos aquí un buen ejemplo, a mi juicio, del tipo de problemas filosóficos que se resuelven, como decía Wittgenstein, enseñando a la mosca a salir de la botella. En este caso, renunciando a perseguir perfectas necesidades y contentándose con explicar las cosas como son, casi siempre irremediablemente contingentes e impuras. La conclusión que parece desprenderse de todo lo dicho anteriormente es que Hart termina fracasando en su empeño por defender a toda costa la tesis de la desconexión entre Derecho y moral; lo cual es tanto como decir que su Teoría del Derecho, pese a sus muchas aportaciones de valor perdurable, también fracasa en cuanto teoría positivista ${ }^{14}$.

Por lo demás, y volviendo al tema de las concesiones que hizo Hart al admitir que la regla de reconocimiento podía contener exigencias morales o de justicia como criterios de validez, hay que decir que tales concesiones configuran un nuevo tipo de positivismo jurídico, que él denomina blando, suave o flexible. En él se inspira la mayor parte de las versiones matizadas y más o menos claudicantes del positivismo jurídico que tanto han proliferado últimamente: positivismo incluyente, corregido, institucionalista, comprehensivo, etc. No vamos a detenernos en el examen de cada una de estas versiones blandas del positivismo. Muchas de ellas se pueden considerar razonables y hasta plausibles en cuanto a sus propuestas teóricas, pero resulta dudoso que se puedan seguir considerando auténticamente positivistas ${ }^{15}$.

14 Presenté una versión ligeramente distinta de la contenida en las páginas anteriores como ponencia en el homenaje al Prof. Delgado Pinto que tuvo lugar en la Universidad de Oviedo durante los días 4 y 5 de noviembre de 2004.

15 Vid., al respecto, Escudero AldAY, R., Los calificativos del positivismo jurídico. El debate sobre la incorporación de la moral, Madrid, Civitas, 2004. Resulta llamativo, aunque comprensible, que, decepcionado por la debilidad de los neopositivismos examinados, que casi sólo tienen en común lo escasamente positivistas que son, el autor termine proponiendo, como tabla de salvación, una especie de vuelta a Hart. Pero volver a Hart significa enfrentarse de nuevo con los arduos problemas que aquí hemos recapitulado (entre otros). 
$\mathrm{Al}$ igual que hemos hecho en la sección anterior con la teoría del Derecho de Hart, mostrando sus incongruencias o tensiones internas, seleccionaremos ahora algunos puntos nucleares de su teoría de la justicia que parecen difícilmente conciliables con esa misma teoría del Derecho. No tanto con la teoría del Derecho implícita o latente en algunos de los aspectos conflictivos más arriba destacados, cuanto con la derivada de la tesis que Hart considera central en su concepción del Derecho y que la configura como una concepción positivista, la tesis de la inexistencia de relación necesaria alguna entre el Derecho y la moral.

Hay que comenzar advirtiendo que, a diferencia de lo que ocurre con la teoría del Derecho, ampliamente desarrollada por nuestro autor, al menos en lo que afecta a la estructura básica, su teoría de la justicia no ha recibido un tratamiento sistemático similar. Son numerosos, sin embargo, los escritos de Hart que pueden encuadrarse en esta rama de la filosofía jurídica y que permiten reconstruir, al menos parcialmente, su pensamiento.

Además de las interesantes consideraciones que bajo el título de "Justicia y moral" ocupan el capítulo octavo de su obra principal, El concepto de Derecho ${ }^{16}$, Hart dedicó varios trabajos al estudio de los derechos naturales, por no hablar de su desconcertante aportación, aunque jibarizada o reducida al contenido mínimo, a la doctrina iusnaturalista. Abordó también diversos problemas de filosofía política y moral relacionados con el Derecho, entre los que destaca el de la imposición de la moralidad por medio de las leyes penales. En este asunto defendió con gran ardor y fuerza persuasiva la libertad moral, y más concretamente la libertad sexual frente a las pretensiones moralistas,

${ }_{16}$ Resulta paradójico que el mismo autor que niega la existencia de toda relación conceptual entre el Derecho y la moral, es decir, que sostiene que ninguna referencia a la moral ha de formar parte del concepto de Derecho, haya considerado necesario incluir una amplia investigación sobre la moral y la justicia en su propia exposición del concepto de Derecho, desplegada en el famoso libro que lleva ese mismo título. 
paternalistas o conservadoras que abogaban por la represión de la homosexualidad y la prostitución, entre otras muchas cosas.

Suele decirse y no sin razón que la actitud adoptada por Hart en estas cuestiones se encuadra en el marco de un utilitarismo moderado o corregido no muy alejado del que desarrolló en su día J. S. Mill. Lo que puede afirmarse con cierta seguridad es que no fue Hart, como no lo fueron sus maestros o precursores utilitaristas, éticamente agnóstico ${ }^{17}$. Quien sostenga que el agnosticismo ético es la actitud más coherente (o incluso la única coherente) con el positivismo jurídico, tendrá que llegar a la conclusión de que en la filosofía del Derecho de Hart no hay congruencia entre teoría del Derecho y teoría de la justicia.

Centraremos esta revisión o reconstrucción parcial de la teoría de la justicia de Hart en su concepción del Derecho natural y de los derechos naturales. Su más conocida aportación al iusnaturalismo es la doctrina del contenido mínimo del Derecho natural ${ }^{18}$. Parte del hecho evidente de que los hombres, como cualquier otro ser vivo, en general desean mantener su existencia. La supervivencia es, pues, una meta o aspiración humana que puede considerarse indiscutible en términos generales. Ahora bien, como afirma Hume, que es el inspirador más directo, junto con Hobbes, de la doctrina que nos ocupa, "la naturaleza humana no

${ }_{17}$ Cfr. HaRt, H. L. A., "Positivism and the Separation of Law and Morals", op. cit., p. 58. Después de enumerar los cinco famosos significados que atribuye al positivismo jurídico e incluir entre ellos el agnosticismo ético, afirma expresamente que Bentham y Austin no suscribieron este significado. Hart tampoco lo suscribió, como prueban sus frecuentes discusiones y tomas de postura sobre algunos de los más candentes problemas morales que se le plantearon (homosexualidad, prostitución, aborto, eutanasia, pena de muerte, etc.); aunque también es cierto que en ocasiones muestra ciertas reticencias hacia lo que llama "teoría objetivista de la moral", y siempre evita pronunciarse sobre el estatuto epistemológico de las proposiciones morales.

18 Aparece desarrollada en El concepto de Derecho, op. cit., pp. 236-47. Anteriormente, Hart había esbozado esta misma doctrina en "Positivism and the Separation of Law and Morals", op. cit., pp. 79-82. Volvió sobre el tema en "Problems of the Philosophy of Law", op. cit., pp. 112-4. Vid. también, al respecto, RIVAYA, B., "Teorías sobre la teoría del contenido mínimo del Derecho natural", en Boletín de la Fac. de Derecho de la UNED, n. 15, 2000, pp. 39-66. 
puede en modo alguno subsistir sin la asociación de individuos; y esa asociación nunca podría tener lugar si no se respetaran las leyes de la equidad y de la justicia"19. En una línea similar, se pregunta Hart si entre las medidas sociales necesarias para hacer posible la existencia continuada del ser humano hay "leyes naturales descubribles por la razón y cuál es su relación con el Derecho y con la moral de los hombres" 20 .

Presupuesto el objetivo de la supervivencia, si se tienen en cuenta algunas características igualmente indiscutibles de la naturaleza humana y del mundo en que nos ha tocado vivir, es inevitable llegar a la conclusión de que existen ciertas reglas de conducta, comunes al Derecho y a la moral social, que toda agrupación humana tiene que adoptar necesariamente para ser viable. Esas reglas o principios de conducta "pueden ser considerados como el contenido mínimo del Derecho Natural"21. Si no se dieran las condiciones que constituyen la razón de ser del Derecho natural, los hombres no tendrían razones comunes para obedecer las normas jurídicas y morales, y sin tal obediencia o cooperación voluntaria general sería imposible el mantenimiento de un orden jurídico que pudiera imponerse coactivamente a los infractores de sus preceptos.

No es necesario, para los propósitos de este trabajo, analizar en detalle las diversas "verdades obvias" sobre la naturaleza humana identificadas por Hart como razón de ser de las más básicas normas jurídicas y morales. Se clasifican en cinco apartados: $1^{\circ}$ ) La vulnerabilidad, $2^{\circ}$ ) La igualdad aproximada, $3^{\circ}$ ) El altruismo limitado, $4^{\circ}$ ) La limitación de recursos y $5^{\circ}$ ) La limitación de la comprensión y de la fuerza de voluntad. La primera de estas evidencias reclama (si se presupone el fin de la supervivencia huma-

19 Texto citado por Hart en El concepto de Derecho, op. cit., p. 237 (extraído del Tratado de la naturaleza humana, Libro III: "De la moral", Parte II: "De la justicia y la injusticia”, pp. 699 y ss., trad. de F. Duque, Madrid, Ed. Nacional, 1981, vol. II.

${ }^{20}$ Cfr. El concepto de Derecho, op. cit., p. 238.

${ }^{21}$ Ibíd., p. 239. 
na) reglas que prohiban el daño a otros. Las más obvias son las que restringen el uso de la violencia, prohibiendo el homicidio, las lesiones, etc. La segunda exige reglas que hagan posible la asunción de compromisos mutuos u obligaciones morales y jurídicas. Las restantes evidencias justifican la presencia de reglas que organicen y protejan alguna forma de propiedad, reglas que hagan posible la distribución y el intercambio de bienes o el cumplimiento de promesas y contratos, reglas que prevean las sanciones aplicables a los infractores, etc.

Estas verdades que a Hart le parecen obvias y de vital importancia para la comprensión del Derecho, "desvelan el núcleo de buen sentido que hay en la doctrina del Derecho natural" 22 . Demuestran, además, frente a una de las tesis más provocadoras del positivismo jurídico, que no es cierto que el Derecho pueda tener "cualquier contenido". Resulta sorprendente que un autor declaradamente positivista se dedique a refutar tan eficazmente tesis positivistas que, aunque radicales, no afectan a aspectos marginales o prescindibles del positivismo jurídico, como la teoría imperativista, también refutada por Hart, sino a la tesis central de esa corriente de pensamiento, la tesis de la desconexión entre el Derecho y la moral. Obviamente, reconocer la falsedad de la tesis de que el Derecho puede tener cualquier contenido es tanto como reconocer la existencia de una conexión necesaria entre el Derecho y ese contenido imprescindible, que bien podría caracterizarse también como moralmente exigible.

Anticipándose a la acusación de incoherencia entre la doctrina del Derecho natural mínimo y la tesis central del positivismo jurídico, Hart viene a decir que nada garantiza que las reglas antes apuntadas como derivaciones necesarias de ciertos hechos evidentes no pudieran aplicarse injustamente, de tal manera que algún sector social quedara al margen de sus beneficios. El Derecho natural mínimo sería, por tanto, para Hart, algo que, como la moral interna del Derecho puesta de relieve por L. L. Fuller, es

${ }^{22}$ Ibíd., pp. 245-6. 
"compatible con una enorme iniquidad" 23 . Se puede reconocer a Hart que la existencia del Derecho natural mínimo por él admitida no torna imposible la presencia de leyes injustas en cualquier orden jurídico, pero, en la medida en que impone al Derecho la recepción de un contenido moral necesario (aunque escueto y susceptible de aplicaciones no equitativas) debilita notablemente la tesis central del positivismo jurídico ${ }^{24}$.

Pasemos ahora del Derecho natural a los derechos naturales. La actitud que cabría esperar en este tema de un autor como Hart, que defiende una concepción positivista del Derecho, sería la misma o similar a la adoptada por J. Bentham, su admirado precursor, negando la existencia de todo derecho que no haya sido otorgado por el Derecho positivo. Sin embargo, en su artículo "¿Hay derechos naturales?" defiende algo muy diferente. Comienza con esta valerosa afirmación: "Sostendré la tesis de que si hay derechos en el campo moral, entonces se sigue de allí que hay por lo menos un derecho natural, a saber, el derecho igual de todos los hombres a ser libres" 25 .

Es un derecho natural que presenta dos vertientes: la primera consiste en el derecho propio de todo ser humano adulto a que los demás se abstengan de ejercer coerción o restricción alguna que le impida obrar conforme a su elección. La segunda consiste en la libertad de realizar cualquier acción que no dañe a otras personas. Se trata además de un derecho que a todos los hombres les

${ }^{23}$ Ibíd., p. 256. En "Positivism and the Separation of Law and Morals", op. cit., p. 81, Hart advierte la posibilidad de que un sistema jurídico que hubiera satisfecho los requerimientos mínimos, pudiera negar a un sector de la población esclavizado y privado de derechos los beneficios mínimos de la protección frente a la violencia y al robo.

${ }^{24}$ Como señala, entre otros, OrRego, C., H. L. A. Hart. Abogado del positivismo jurídico, op. cit., p. 68, "cuando Hart dice que en ningún sentido es una verdad necesaria que las leyes reproducen o satisfacen ciertas exigencias de la moralidad, contradice su propio pensamiento", puesto que también afirma que un contenido mínimo de Derecho natural existe en todo sistema jurídico necesariamente.

${ }^{25}$ Cfr. HaRT, H. L. A., “¿Hay derechos naturales?” en Derecho y moral. Contribuciones a su análisis, trad. de G. R. Carrió, Buenos Aires, Depalma, 1962, p. 65 . 
corresponde "en igualdad", luego tendríamos aquí, al menos en germen, no sólo un derecho a la libertad sino también a la igualdad. Sería, eso sí, un derecho no absoluto o incondicional, puesto que en algunos casos su limitación coactiva podría estar justificada sin que eso anulara el principio general. Pese a no ser un derecho absoluto, irrevocable ni imprescriptible es más importante de lo que puede parecer a primera vista. De hecho "es probablemente todo lo que los filósofos políticos de la tradición liberal necesitaban reivindicar para sustentar cualquier programa de acción" 26 .

Se trata de un derecho natural, argumenta Hart invocando razones que dice compartir con los iusnaturalistas clásicos, porque lo poseen todos los hombres capaces de elección por el mero hecho de ser hombres, sin que deba su existencia a la acción voluntaria de nadie. Pero debe advertirse que la existencia de ese supuesto derecho natural a la igual libertad de todos está sometida a una condición: que existan derechos en el campo de la moral, cosa que Hart considera innegable, porque la noción de derecho en sentido subjetivo es un elemento imprescindible para la rama de la ética que determina cuándo se puede restringir justificadamente la libertad. En efecto, tener un derecho moral es tanto como tener una justificación moral para limitar la libertad de otro. Luego, es evidente que la existencia de los derechos morales presupone la existencia de la libertad como derecho previo que se reconoce a todos por igual.

$\mathrm{Al}$ margen de lo anterior, en este sorprendente artículo, Hart llega a decir que el término Derecho (en sentido objetivo) "delimita un área de moralidad"27. El área a que pertenecen conceptos tales como los de justicia, equidad, derechos y obligaciones. Unos conceptos que tienen en común la admisibilidad del empleo de la fuerza para asegurar que se realice lo justo, lo equitativo, lo que representa el derecho de alguien o lo que es debido jurídicamente.

26 Ibíd., p. 67.

27 Ibíd., p. 70 . 
Otra extraña concesión (para tratarse de un autor adscrito a un positivismo no ideológico sino sólo metodológico) presente en el artículo que nos ocupa es el reconocimiento de la existencia de un deber moral de obedecer el Derecho, fundado en un supuesto deber de lealtad o juego limpio que recae sobre todo aquél que se haya beneficiado del sometimiento a las restricciones jurídicas asumido por sus conciudadanos $^{28}$. Según argumenta Hart, los ciudadanos que cumplen las exigencias jurídicas tienen un derecho moral a idéntico cumplimiento por parte de todos los que se benefician de su sacrificio, y esos otros tienen correlativamente un deber moral de obediencia al Derecho.

Podrá objetarse que el artículo a que nos estamos refiriendo no es representativo del pensamiento maduro de Hart $^{29}$. Pero aunque lo haya repudiado expresamente, representa una pieza significativa de su trayectoria intelectual, y el mismo repudio puede interpretarse como una manifestación explícita de esa contradicción interna a su pensamiento que aquí pretendemos poner de manifiesto. Es más, en los restantes artículos que Hart dedica al problema de los derechos humanos adopta una actitud que, aun siendo menos abierta o directa y más impersonal, puesto que aparece sólo apuntada al hilo de sus comentarios a las doctrinas de otros autores, todavía se encuentra

${ }^{28} \mathrm{El}$ argumento ha encontrado amplio eco en otros autores. Vid., p. ej., RAwLS, J., "Legal Obligation and the Duty of Fair Play", en Law and Philosophy, ed. por S. Hook, New York, 1964; PÉRez BermeJo, J. M., Contrato social y obediencia al Derecho en el pensamiento de John Rawls, Granada, Comares, 1997, pp. 215 y ss.

${ }^{29}$ En la introducción a los Essays in Jurisprudence and Philosophy, loc. cit., p. 17, afirma Hart lo siguiente respecto a dicho artículo de 1955: "aunque logró atraer cierta atención, no lo he incluido aquí porque su principal argumento me parece erróneo". Salva, sin embargo, de la quema "el principio de fair play" como fundamento de la obligación política; y eso es tanto como decir que sigue creyendo en la existencia de un deber moral de obedecer el Derecho. Otros autores, sin embargo, como Maccormick, N., H. L. A. Hart, op. cit., p. 10, confirman la importancia del ensayo en cuestión. Un examen crítico del mismo lleva a cabo MACK, E., "Hart on Natural and Contractual Rights", en Philosophical Studies, vol. 29, 1976, pp. 283 ss. También lo considera defectuoso, aunque le dedica un detallado examen y destaca el hecho de que haya sido un artículo frecuentemente citado y reproducido por los estudiosos, BaYles, M. D., Hart's Legal Philosophy. An Examination, Dordrecht/London, Kluwer Ac. Pub., 1992, pp. 151 ss. 
más próxima a la defendida en el artículo antes examinado que a la que cabría esperar de un positivista estricto.

Un positivista estricto o consecuente criticaría la idea de los derechos humanos en una línea no demasiado disímil de la seguida por Bentham, que los considera simples gritos en el vacío, puesto que al no ser creaciones del Derecho positivo, no hay criterio alguno para determinar cuáles son esos derechos ni cuáles son sus límites, y será finalmente el capricho interesado de ciertos individuos lo que los determine. Hart, sin embargo, aunque una y otra vez parte del examen complaciente de las críticas de Benthan a los derechos naturales y aunque deja caer la sugerencia de que la acusación de falta de criterio no ha sido refutada aún convincentemente, no parece considerar tales críticas del todo satisfactorias. Su adhesión se decanta más bien hacia la postura adoptada por J. S. Mill, discípulo un tanto heterodoxo de Bentham, que no cree posible articular una adecuada teoría de la justicia sin hacer referencia a los derechos morales de las personas, pues para él la justicia consiste básicamente en el respeto a esos derechos. En consecuencia, Mill procura conciliar derechos humanos y utilitarismo, intentando demostrar que la doctrina de la utilidad general es la base de los derechos individuales, puesto que nada hay más útil para los seres humanos que la libertad y los otros supremos intereses protegidos por los derechos humanos. Así pues, aunque las decisiones políticas deban perseguir la maximización de la utilidad, no deberán hacerlo a costa de los derechos individuales y tendrán su límite en la necesidad de respetar esas exigencias de justicia que, como el derecho a la libertad, sólo podrán restringirse para evitar del daño a otros ${ }^{30}$.

${ }^{30}$ Literalmente afirma HART, H. L. A., "Utilitarismo y derechos naturales", trad. de J. R. de Páramo, en Anuario de derechos humanos, vol. 1, 1981, p. 162, que "la doctrina de la libertad de Mill es en este punto una desviación sugestiva del principio maximizador del utilitarismo, siendo su efecto el asegurar a cada individuo un área de libertad para el campo total de sus actividades no perjudiciales. Al ofrecer esta protección de la libertad de los individuos como tales, asegura el mismo área de libertad para todos los individuos, siendo así una medida de igualdad, mientras que el utilitarismo puro no está comprometido en ningún 
Aunque Hart también parece considerar deseable alguna forma de conciliación entre el utilitarismo y las doctrinas de los derechos humanos, que limite la búsqueda de la máxima utilidad social mediante el respeto a la importancia moral de la dignidad de las personas, no cree que esa conciliación haya sido lograda convincentemente por Mill. Frente a las suposiciones de Mill, Hart niega que la utilidad general pueda servir como criterio para identificar los derechos humanos. La afirmación de que la gente tiene derechos humanos no puede justificarse por referencias a consideraciones de bienestar general, sino sólo por referencia al bien individual de sus titulares. Mill supone que la razón para proteger los derechos individuales es la utilidad general, pero olvida que si la utilidad general pudiera incrementarse negando dicho bien a alguna minoría, el utilitarismo, que no respeta la individualidad de las personas, recomendaría tal negación. Luego, no puede ser la utilidad general el verdadero fundamento de los derechos humanos.

Hart advierte, sin embargo, que en el pensamiento de Mill es posible encontrar fundamentos teóricos para limitar los posibles excesos del utilitarismo e impedir el sacrificio de los derechos de alguna minoría en aras del bienestar general, apelando a su famoso principio de libertad, puesto que la libertad consagrada por este principio sólo puede restringirse para evitar el daño a otros. Es cierto que la libertad puede considerarse uno de los componentes esenciales de la felicidad humana, pero el principio de libertad no busca aumentar la suma total de bienestar social. No es agregativo sino individual o distributivo. La prueba de que el principio de libertad no tiene un fundamento utilitarista es que Mill sólo admite su limitación para evitar el daño a otros, mientras que si tuviera una base utilitarista tendría que admitir muchas otras limita-

sentido con la igualdad de trato como un valor independiente." Como es fácil advertir, esta doctrina de Mill que Hart examina, recuerda bastante al igual derecho natural de todos los hombres a ser libres que él mismo había defendido en “Hay derechos naturales?” 
ciones. No es verdad, en suma, que los derechos humanos puedan identificarse porque su reconocimiento venga exigido por la utilidad general.

Aparte de lo anterior, Mill acierta, en opinión de Hart, al identificar como derechos las formas del bien individual que son componentes esenciales de la felicidad humana. Se trata de una aportación vaga y discutible, pero Hart la considera valiosa, y de ella deduce que para dar sentido a la noción de los derechos morales universales o derechos humanos es necesario elaborar una teoría de las necesidades básicas de los individuos y de lo que pueden razonablemente demandar de los demás (por vía de abstención o de provisión positiva) a fin de perseguir sus propios fines ${ }^{31}$. En otro lugar, extrae del pensamiento de Mill una conclusión similar, la de que "una teoría de los derechos individuales básicos debe apoyarse en una concepción específica de la persona y de lo que es necesario para el ejercicio y desarrollo de las facultades humanas características"32.

Es evidente que la actitud adoptada aquí por Hart hacia la idea de los derechos humanos es más positiva que positivista. En efecto, aunque suele considerársele un pensador positivista y utilitarista, bastante matizado en todo caso, él reconoce expresamente que la defensa de una doctrina de los derechos humanos es lo que requiere con mayor urgencia la realidad de nuestra época, permanentemente amenazada por la barbarie del hombre contra el hombre, y que tal requerimiento es más importante que la conveniencia de maximizar la utilidad general. Pese a todo, sigue echando en falta "una teoría suficientemente detallada o adecuadamente articulada que muestre el fundamento de tales derechos y su relación con otros valores perseguidos por el gobierno" 33 . Al igual que ocurre con

${ }^{31}$ Cfr. HaRT, H. L. A., "Natural Rights: Bentham and J. S. Mill", en Essays on Bentham..., loc. cit., p. 103. (Hay trad. al castellano de J. R. de Páramo, en Anuario de derechos humanos, vol. 3, 1984).

${ }^{32}$ Cfr. HART, H. L. A., Introducción a sus Essays in Jurisprudence and Philosophy, loc. cit., p. 17. No es necesario llamar la atención sobre el fuerte sabor iusnaturalista de la afirmación citada.

${ }^{33}$ Cfr. HaRT, H. L. A., "Utilitarismo y derechos naturales", op. cit., p. 166. 
otros positivistas moderados, como N. Bobbio, parece que una de las mayores reticencias que mantiene Hart hacia los derechos humanos es la dificultad de hallarles un fundamento sólido.

La percepción de la dificultad apuntada está en la base de sus críticas a algunas de las últimas teorías ético-políticas que se han propuesto revitalizar la doctrina de los derechos individuales básicos. El grueso de la crítica se despliega en su artículo "Entre el principio de utilidad y los derechos humanos" 34 . Parte allí de la constatación del profundo cambio acaecido en la filosofía política angloamericana actual, que ha abdicado de su vieja fe en el utilitarismo como esencia de la moral política, abrazando la nueva fe en la doctrina de los derechos humanos como elementos protectores de las libertades e intereses básicos de las personas. La crítica de Hart se concentra en dos versiones (una liberal-conservadora y la otra izquierdista o igualitarista) de esa doctrina "que deslumbra tanto como ilumina" ${ }^{35}$. La primera es la defendida por R. Nozick basándose en la importancia moral de la individualidad específica de cada ser humano, y la segunda la defendida por R. Dworkin partiendo de la importancia moral del derecho de las personas a una igual consideración y respeto ${ }^{36}$.

No es necesario examinar con detalle las sutiles objeciones de Hart a estas doctrinas. Baste destacar que en el transcurso de su análisis reconoce una vez más la insuficiencia del utilitarismo, incapaz de tomarse en serio la importancia de la individualidad de las personas y la necesidad de una distribución justa adecuada a esa realidad. No cree admisible, sin embargo, que se abuse de esa justa crítica al utilitarismo, como hace Nozick, utilizándola para desacreditar cualquier intento de reducir las desigualdades sociales. Una de las críticas que dirige a Nozick le acusa de no demostrar que los seres humanos tengan sólo de-

34 Trad. por M. D. González, F. Laporta y L. Hierro, en la Revista de la Facultad de Derecho de la Universidad Complutense, vol. 58, 1980, pp. 7-28.

${ }^{35}$ Ibíd., p. 7.

36 Vid. Nozick, R., Anarquía, Estado y utopía, trad. de R. Tamayo, México, F.C.E., 1988, y Dworkin, R., Los derechos en serio, op. cit. 
rechos de libertad que obliguen al Estado a convertirse en un simple vigilante nocturno. Obviamente, Hart está aquí abogando por los derechos sociales y económicos. ¿Por qué no habría de incluirse, se pregunta Hart, el derecho fundamental a una acción positiva del Estado encaminada al alivio de graves necesidades o sufrimientos, o al mantenimiento de la educación y capacitación profesional básica? "Para una vida con sentido no sólo hay que proteger la libertad. También son necesarias las oportunidades y los recursos para su ejercicio" 37 . Se puede llegar, por tanto, a la conclusión de que Hart no critica la doctrina de Nozick por basarse en la defensa de los derechos humanos, sino por defenderlos sólo parcialmente, excluyendo del derecho a la libertad el derecho a las condiciones materiales necesarias para que esa libertad contribuya al pleno bienestar del hombre.

En cuanto a la crítica que dedica al pensamiento de Dworkin en este artículo, también parte del reconocimiento de que los argumentos utilitaristas, aun convenientemente matizados, "pueden producir resultados antiliberales y toscamente desigualitarios" 38 ; y termina con una encendida defensa de la libertad, que, en su opinión, debe organizarse sobre bases distintas a las de la igualdad, puesto que la igualdad no garantiza la libertad. Sería posible tratar a todos con idéntica consideración y respeto negándoles la libertad por igual. Para proteger algo tan valioso en la vida humana como la libertad "necesitamos derechos que son desde luego antiutilitaristas, pero también anti muchas otras cosas" 39 , frente a las cuales deben prevalecer como escudos protectores.

Pese a las concesiones anteriores, Hart insiste de nuevo en que "ha de hacerse mucho más para identificar los rasgos peculiares de la dimensión de moralidad que constituye la concepción de los derechos fundamentales y el modo en que esa dimensión de moralidad se relaciona con otros valo-

\footnotetext{
37 Ibíd., pp. 15-6

38 Ibíd., p. 26.

39 Ibíd., p. 27.
} 
res perseguidos a través del gobierno" 40 . En general, parece sugerir que una teoría satisfactoria de los derechos humanos no debe construirse únicamente a partir del rechazo a los defectos del utilitarismo sino también tanteando la posibilidad de lograr alguna armonización con sus aciertos. En todo caso, advierte que todavía no se ha logrado más que fragmentariamente desarrollar una teoría de los derechos individuales comparable a la teoría utilitarista en claridad y riqueza de detalles. Pero el punto de partida, el respeto a la dignidad y al valor de la persona individual, ausente en Bentham, es algo que Hart considera irrenunciable.

No hay duda, por tanto, de su aceptación de los elementos básicos de la idea de los derechos humanos, y el más básico de todos probablemente sea la aceptación de la existencia de valores morales racionales o universalmente válidos. En uno de los libros más emblemáticos de su filosofía política, Law, liberty and Morality, reconoció entre otras cosas, que toda moral social, sea cual sea su contenido, defiende en alguna medida "valores tan universales como la libertad individual, la seguridad de la vida y la protección frente al daño deliberadamente infligido"41. Vida, libertad, seguridad, etc., forman obviamente el substrato axiológico de los principales derechos del hombre. Curiosamente, Hart afirma, frente a la suposición de Lord Devlin, que la moral no tiene valor porque asegure estos elementos necesarios para la preservación de la sociedad, sino que "la preservación de cualquier sociedad tiene valor porque, entre otras cosas, asegura para los seres humanos alguna medida de estos valores universales"42. Aquí resuena claramente el alegato del artículo segundo de la Decla-

40 Ibíd., p. 28. Algo similar afirma en "1776-1976: Law in the Perspective of Philosophy", en Essays in J..., loc. cit., p. 152: "No creo que tengamos aún una teoría satisfactoria que muestre cómo se ha de combinar el respeto por los derechos humanos básicos con la persecución de otros valores. Algunas teorías parecen arrojar al bebé (que sería el conjunto de los derechos básicos compatibles entre sí y con el ejercicio del gobierno) junto con el agua del baño de una rigidez excesiva. Otras teorías (quizá entre ellas la del Prof. Nozick) hacen algo aún peor: arrojan al bebé y conservan el agua del baño.

${ }^{41}$ Cfr. HaRT, H. L. A., Law, Liberty and Morality, Oxford, OUP, 1963, p. 70.

${ }^{42}$ Ibíd. 
ración francesa de los derechos del hombre y del ciudadano de 1789 , que tanto irritaba a Bentham y que representaba la negación de utilitarismo. La proclama de que el fin de toda sociedad política es la preservación de los derechos naturales e imprescriptibles del hombre, y no al revés.

Debemos preguntarnos ahora si la teoría de la justicia y de los derechos individuales que emerge de los aspectos examinados en la obra de Hart es compatible con su teoría positivista del Derecho ${ }^{43}$. Obviamente, la respuesta tendría que ser rotundamente negativa si no fuera porque Hart asume una de las tesis centrales de sus precursores utilitaristas y positivistas, J. Bentham y J. Austin, la tesis de la separación radical entre lo que es Derecho y lo que debería ser Derecho. Una cosa es la existencia del Derecho, el Derecho tal y como realmente es, que se decide mediante los criterios, normalmente formales o en todo caso no necesariamente materiales, previstos por la regla de reconocimiento de cada sistema jurídico, y otra cosa completamente distinta es su mérito o demérito. El filósofo del Derecho puede especular sobre lo justo, sobre los valores e ideales que el Derecho debería realizar, sobre las reformas jurídicas exigidas por la moral social o por la moral crítica, pero esas operaciones no tienen nada que ver con la operación consistente en identificar el Derecho válido, el Derecho realmente existente ${ }^{44}$.

43 OrRego, C., H. L. A. Hart. Abogado del positivismo jurídico, op. cit., p. 415, apunta la siguiente impresión: "Hart necesitaba alguna forma de positivismo metodológico para justificar la separación entre su labor como moralista crítico y sus argumentos como filósofo especulativo; pero lógicamente, el conflicto de ideas resulta patente cuando se relacionan ambos aspectos de su pensamiento".

${ }^{44}$ Cfr., p. ej., HART, H. L. A., "Positivism and the Separation of Law and Morals", op. cit., pp. 50 y ss.; "El nuevo desafío al positivismo jurídico", op. cit., pp. 4-5. En opinión de Moles, R. N., Definition \& Rule in Legal Theory. A Reassessment of H. L. A. Hart and the Positivist Tradition, Oxford/New York, Blackwell, 1987, pp. 207 ss., Hart no interpretó correctamente el pensamiento de J. Austin cuando le atribuyó la tesis de la separación estricta entre Derecho y moral. Es cierto, reconoce Moles, que Austin sostuvo, a fin de lograr una mejor comprensión tanto del Derecho como de la moral la necesidad de examinarlos por separado, pero también advirtió expresamente que ambos órdenes normativos "son las partes inseparablemente conectadas de una gran totalidad orgánica." Además de malinterpretar la posición de Austin, según sugiere Moles, Hart habría incurrido en una confusión epistemológica, pues dos fenómenos pueden ser distintos y sin embargo estar estrechamente relacionados. 
Si esta tesis fuera admisible, entonces no se sostendría nuestro punto de partida, la idea del Prof. Delgado Pinto que cifra el valor de cualquier Filosofía del Derecho en la coherencia de su teoría del Derecho, su teoría de la justicia y su teoría del razonamiento jurídico, entre ellas y también con la realidad de la práctica jurídica cotidiana. Es más, forzando un poco los términos, podríamos afirmar que si fuera irreprochable la tesis de la separación estricta entre el Derecho que es y el Derecho que debería ser, sería también perfectamente irreprochable declararse al mismo tiempo positivista y iusnaturalista. Positivista en cuanto a la determinación de lo que el Derecho es y iusnaturalista en la determinación de lo que debe ser. Quizá fuera esa en algún momento de su trayectoria académica la aspiración inconfesada de Hart, quien, no lo olvidemos, se declara positivista al mismo tiempo que defiende una teoría del contenido mínimo del Derecho natural.

En mi opinión, resulta difícilmente sostenible la tesis de la separación estricta entre el Derecho "que es" y el Derecho que "debe ser". Hay que comenzar advirtiendo que la idea del Derecho "que debería ser" admite varios sentidos o niveles, que Hart no acierta a distinguir. Por Derecho "que debería ser" puede entenderse el proyecto idealizado de un orden jurídico más perfecto o deseable que el vigente. Ciertamente, ese ideal de Derecho, frecuentemente distinto en la mente de cada filósofo del Derecho o reformador social, podría apartarse en mayor o menor medida del Derecho realmente existente. Pero también puede entenderse por Derecho que debe ser, el orden resultante de la aplicación e interpretación de las normas jurídicas válidas a la luz de los principios y valores que les dan sentido o justificación, y marcan el rumbo que el Derecho ha de seguir, especialmente en la resolución de los casos difíciles. Parece obvio que en este último sentido, el Derecho "que debe ser", no puede distinguirse ni separarse del Derecho "que es".

Igualmente admite varios sentidos o niveles la idea del Derecho "que es". Por Derecho "que es" puede entenderse el conjunto de normas jurídicas dictadas por los órganos 
autorizados conforme al procedimiento previsto y que, por eso mismo, pueden considerarse válidas, aunque en algún caso no sean como deberían ser. La posibilidad de una creación voluntaria de normas, que en principio pueden ser defectuosas, tanto técnica como moralmente, es una peculiaridad del Derecho como fenómeno institucionalizado que es.

Pero por Derecho "que es" puede entenderse también, en un nivel más amplio, el fenómeno social que constituye el orden jurídico en su conjunto, con su peculiar sentido, propósito o función en la vida social, que no podría desempeñar si no respetara ciertos valores morales, básicamente la justicia, o si no reconociera los derechos humanos básicos, o si no se propusiera ciertos fines u objetivos sociales que pueden resumirse en el bien común. Estos rasgos materiales, que hacen al Derecho inteligible para nosotros como conjunto de prácticas e instituciones, forman parte también del ser del Derecho, de lo que el Derecho "es" en su conjunto ${ }^{45}$. Obviamente, en este sentido, lo que el Derecho "es" no puede distinguirse de lo que "debe ser".

En definitiva, la tesis de la separación estricta entre el Derecho "que es" y el "que debe ser" puede considerarse una generalización apresurada a partir de algunos aspectos parciales o rasgos concretos del fenómeno jurídico, cuya presencia es innegable pero que no agotan la realidad del fenómeno. Cuando se contempla el sentido global del orden jurídico en la vida social es necesario corregir o matizar esa generalización apresurada. Si lo anterior es correcto, no resulta nada extraño que Hart se haya visto obligado a mati-

45 Incluso un autor positivista, y en alguna medida discípulo o continuador de Hart, como MACCORMiCK, N., "Natural Law and the Separation of Law and Morals", en Natural Law Theory. Contemporary Essays, ed. por R. P. George, Oxford, Clarendon Press, 1992, p. 113, reconoce que "es tan verdad en relación con el Derecho que la justicia y la promoción del bien común dentro de los límites de la justicia son los bienes particulares que lo hacen inteligible para nosotros como conjunto de prácticas e instituciones, como es verdad en relación con el arte que su finalidad es la comunicación de la experiencia estética a través de la originalidad creativa". "La conclusión general es que las normas del Derecho, como otras instituciones sociales, sólo son completamente inteligibles por referencia a los fines o valores que deben realizar". 
zar tantas veces su tesis de la desconexión entre el Derecho y la moral, reconociendo entre ambos innumerables conexiones, que él minimiza calificándolas como contingentes. Ya discutimos la supuesta contingencia de tales conexiones en la primera sección de este trabajo, centrada en el examen de la coherencia interna de la concepción hartiana del Derecho "que es", y me remito a lo que dije allí.

La cuestión que ahora debemos plantearnos es la de cuál de los dos sentidos antes distinguidos del Derecho "que debe ser" es el que corresponde a las aportaciones de Hart a la teoría de la justicia. ¿Representan esas aportaciones ideales alternativos tendentes a reformar el Derecho vigente, o forman parte de la moral subyacente a ese mismo Derecho? Creo que no son lo primero, porque la postulación de un contenido mínimo del Derecho natural común a todo orden jurídico y moral, o del valor de la libertad y la dignidad humana como derechos individuales, son presupuestos tan básicos de cualquier Derecho que no se pueden considerar ideales alternativos de justicia o proyectos idealizados de un orden jurídico más deseable que el vigente. ¿Podemos encuadrarlos entonces entre los valores o principios implícitos en las normas jurídicas existentes? Aunque sean valores últimos o muy abstractos, sin duda son imprescindibles para dar sentido, no sólo al Derecho inglés o al español, sino también al Derecho de cualquier sociedad civilizada. En este sentido, se pueden considerar elementos implícitos en esos ordenamientos, y por tanto, parte integrante de los mismos.

En cualquier caso, el ámbito en el que es posible probar o descartar la implicación del Derecho "que debe ser", es decir, de la moral subyacente al orden jurídico, en la constitución del Derecho "que es", constitución que actualizan cotidianamente los jueces cuando interpretan y aplican las normas, especialmente en los casos difíciles, es el ámbito del razonamiento jurídico. Quienes han ahondado en este campo de estudio y han constatado la profunda influencia que tienen en la resolución de los conflictos jurídicos los principios, valores y objetivos del Derecho, que inevitablemente lo enlazan con la moral social, no pueden dejar de advertir al 
mismo tiempo la insuficiencia de la filosofía del Derecho positivista, incapaz de ofrecer una explicación satisfactoria de esa práctica jurídica efectiva. Insatisfactoria es, por ejemplo, la teoría de Kelsen de la interpretación jurídica, que la concibe como un mero despliegue de todos los posibles significados de cada norma, y que deja al juez, en el ejercicio inescrutable de su voluntad autorizada, la posibilidad de optar por cualquiera de ellos, que en principio tienen el mismo valor ${ }^{46}$. No muy distinta es la concepción de Hart, que, como explicamos al comienzo, sostiene que allí donde las normas jurídicas no resuelven claramente un caso, lo ha de resolver la discrecionalidad judicial, que no tiene por qué ser arbitraria en el sentido de insensata, pero que, en último término, no se apoya en el Derecho vigente.

La teoría del razonamiento jurídico que emerge de la concepción hartiana de la discrecionalidad judicial creadora de Derecho es muy pobre y no da cuenta satisfactoriamente de la práctica efectiva que se produce cada día en la aplicación del Derecho por parte de los tribunales de justicia. El propio Hart era consciente de la debilidad de sus aportaciones a esta rama de la filosofía jurídica y así lo reconoció en el Postscript a la segunda edición de su obra

${ }^{46}$ Cfr. KelSen, H., Teoría pura del Derecho, trad. de R. J. Vernengo, México, UNAM, 1979, pp. 349 ss. Debe advertirse que algunos autores, aun reconociendo que el desarrollo actual de la teorías de la argumentación jurídica ofrece nuevas evidencias de la vinculación entre el Derecho y la moral, y en ese sentido es tendencialmente antipositivista, creen posible mantener en pie la doctrina positivista, al menos, de la discrecionalidad judicial; porque aun aplicando los criterios morales descubiertos por la teoría de la argumentación, siempre quedará un margen de elección o discrecionalidad para los jueces. Cfr., p. ej., PRIETO SANCHIS, L., Constitucionalismo y positivismo, México, Fontamara, 1997, pp. 42 ss. La duda que aquí se plantea, a mi juicio, es la de si ese residuo de discrecionalidad judicial irreductible basta para mantener las constantes vitales del positivismo jurídico, teniendo en cuenta que las teorías de la argumentación (entre otras) tornan cada vez más insostenible su tesis central, la que niega la existencia de conexiones necesarias entre Derecho y moral. Sobre esta problemática, vid., p. ej., Ansuategui Roig, F. J., "Positivismo y teoría de la argumentación jurídica"; García FigueroA, A., "Haciendo justicia desde el lado activo del Derecho. Teoría de la argumentación y teoría del Derecho"; Oliva Ekelund, C., "La teoría de la argumentación y el positivismo jurídico", trabajos recogidos en Sobre el razonamiento jurídico, Revista de Ciencias Sociales (Valparaíso, Chile), nº. 45, pp. 359-82, 193-218 y 731-65, respectivamente. 
principal, que se ha venido considerando una especie de testamento iusfilosófico ${ }^{47}$. Resulta llamativo, aunque comprensible, que aquella parte de la filosofía del Derecho, la teoría del razonamiento jurídico, que hubiera permitido a Hart poner a prueba (y seguramente abandonar o matizar drásticamente) la teoría de la separación estricta entre el Derecho que es y el que debe ser (o entre teoría del Derecho y teoría de la justicia), brille por su ausencia o al menos destaque por su raquitismo en su obra, y quizá esa sea la razón por la que no encontró serios obstáculos para defender algo tan contraintuitivo. ¿No es acaso contraintuitivo que una realidad normativa como el Derecho, es decir, una realidad que establece "lo que debe ser", no tenga nada que ver con lo que debe ser Derecho?

Terminaré con una breve referencia a una de las pocas incursiones de Hart en el campo del razonamiento jurídico, en la que discute la resolución judicial de un caso difícil. Creo que ejemplifica bien la idea que intento defender, la idea de que en el campo del razonamiento jurídico se pone en evidencia, a poco que se escarbe, la conexión entre lo que es Derecho y lo que debe ser Derecho. Me refiero a las reflexiones de nuestro autor sobre cuál sería la mejor forma de juzgar las atrocidades cometidas en la Alemania nazi por individuos que las realizaron al abrigo de las leyes inicuas entonces vigentes ${ }^{48}$.

Frente a G. Radbruch, que propone condenarlas por vulnerar principios básicos de la moral o exigencias intem-

47 Cfr. HaRT, H. L. A., Postscript a la $2^{\mathrm{a}}$ ed. de The Concept of Law, Oxford, OUP, 1994, p. 259: "Pero ciertamente deseo confesar ahora que dije demasiado poco en mi libro sobre el tema de la decisión judicial y del razonamiento jurídico, y en particular sobre la discusión de lo que mis críticos llaman principios jurídicos. Estoy de acuerdo en que es un defecto de este libro que los principios se toquen sólo de pasada".

Es curioso advertir que la mayor parte de las ideas contenidas en el "Postscript", que tanto revuelo ha provocado entre los estudiosos, coinciden (hay párrafos enteros literalmente idénticos) con las que ya estaban expuestas en "El nuevo desafío al positivismo jurídico", op. cit., artículo que traduce el texto de una conferencia pronunciada por Hart en la Univ. Autónoma de Madrid en 1979, y que sólo se publicó en español.

48 Cfr. HART, H. L. A., "Positivism and the Separation of Law and Morals", op. cit., pp. 75-8. Vid. también El concepto de derecho, op. cit., pp. 257-61 y 322-3. 
porales de justicia (de lo que debería ser Derecho), Hart considera preferible que la condena se base en una ley positiva, aunque tenga que ser francamente retroactiva, por mucho que esto parezca poco elegante desde el punto de vista técnico-jurídico o incluso un mal moral, aunque un mal menor que dejar impunes los desmanes. Ahora bien, Hart está presuponiendo aquí lo que quiere negar, es decir, que aquellos actos inmorales, justamente por ser gravemente inmorales, deben condenarse jurídicamente y sus autores deben ser castigados. Que la represión se apoye en una ley retroactiva es sólo una forma pretendidamente positivista de presentar una solución que, sin embargo, no se habría podido tomar si se hubiera aplicado al caso un planteamiento estrictamente positivista, pues entonces los acusados tendrían que haber sido absueltos, dado que se limitaron a cumplir las leyes vigentes (se supone que la injusticia de las leyes es algo irrelevante para el positivismo jurídico). En otras palabras, la solución propuesta por Hart a fin de resolver estos casos difíciles supone la aplicación del Derecho "que debería ser", aunque se presente como Derecho "que es", dictado retroactivamente para cubrir la apariencias de buena positividad.

En resumen, la teoría del Derecho de Hart, aun ofreciendo elementos que siguen siendo muy aprovechables aisladamente considerados, tiene en su interior rasgos contradictorios y es, a su vez, contradictoria, en lo que tiene de positivista, con su teoría de la justicia; cosa que habría podido advertir si hubiera desarrollado una adecuada teoría del razonamiento jurídico que, salvo algún apunte esquemático, brilla por su ausencia. Lo poco que de ella se vislumbra, la teoría de la discrecionalidad judicial creadora de Derecho, resulta insatisfactorio, porque no da cuenta de la práctica judicial efectiva en la aplicación del Derecho, especialmente en los casos difíciles, inmersos en lagunas o afectados por la inevitable indeterminación de que adolecen las normas. Esa práctica judicial efectiva, que pone en juego derechos, valores y principios jurídico-morales implícitos en el Derecho, dista mucho de consistir en el despliegue de una arbitrariedad más o menos ilustrada. 